\title{
TEORIA DOS VÍNCULOS PROFISSIONAIS: UM NOVO MODO DE GESTÃO EM ENFERMAGEM ${ }^{1}$ \\ THEORY OF PROFESSIONAL LINKS: A NEW METHOD OF NURSING ADMINISTRATION TEORÍA DE LOS VÍNCULOS PROFESIONALES: UN NUEVO MODO DE GESTIÓN EN LA ENFERMERÍA
}

\author{
Maira Buss Thofehrn', Maria Tereza Leopardi $i^{3}$
}

\begin{abstract}
${ }^{1}$ Este estudo é parte da tese de doutorado "Teoria dos vínculos profissionais: uma proposta para o trabalho em equipe na enfermagem”, defendida em fevereiro de 2005, na Universidade Federal de Santa Catarina (UFSC), Florianópolis - SC.

${ }^{2}$ Enfermeira. Doutora em Filosofia da Enfermagem. Professora da Faculdade de Enfermagem e Obstetrícia da Universidade Federal de Pelotas (UFPel). Coordenadora do Núcleo de Estudos em Práticas de Saúde e Enfermagem (NEPEN) da UFPel.

${ }^{3}$ Enfermeira. Doutora em Enfermagem. Coordenadora do Curso de Enfermagem da Universidade do Extremo Sul Catarinense (UNESC). Membro do Núcleo de estudos sobre trabalho, saúde e cidadania (PRÁXIS) da UFSC.
\end{abstract}

PALAVRAS-CHAVE: Enfermagem. Organização e administração. Recursos humanos.

KEYWORDS: Nursing. Organization and administration. Human resources.

PALABRAS CLAVE: Enfermería. Organización y administración. Recursos humanos.
RESUMO: Os estudos sobre administração e gestão em enfermagem, especialmente quanto à dimensão da subjetividade no trabalho, nos instigaram a construir um Modelo para os recursos humanos, para a formação de equipes. Utilizamos uma metodologia qualitativa, com abordagem construtivista. Para teorizar foram utilizados três autores da dinâmica grupal. O conjunto desses estudiosos, da abordagem construtivista e da dinâmica grupal, formaram a matriz teórica do estudo. Visando atender a confiabilidade na pesquisa, foi adotada a triangulação na obtenção dos dados, com a utilização de três técnicas: entrevista semi-estruturada, observação simples e grupo focal. A análise dos dados ocorreu durante todo o processo de coleta e a síntese da análise resultou num conjunto de conceitos sistematizados. Assim, os dados nos levaram para além do Modelo, surgindo a Teoria dos Vínculos Profissionais, que corresponde a um novo modo de gestão para o trabalho em equipe na enfermagem.

ABSTRACT: The studies concerning nursing administration related to the dimension of subjectivity at work have inspired us to build a Model for human resources, or rather, the formation of teams. We use a qualitative methodology with a constructive approach. Three authors of the dynamic group were used to theorize. The gathering of these studious, constructive ideas and team dynamic formed the theoretical matrix of this study. Aiming at responding to the reliability of research, the data was collected through triangulation, using three techniques: semi-structured interview, simple observation, and focus group. The data analysis took place during the whole collection process and the analysis synthesis resulted in a set of systematized concepts. Thus, the data led us beyond the Model, resulting in the Theory of Professional Links, which corresponds to a new way of nursing teamwork management.

RESUMEN: Los estudios acerca de la administración y de la gestión en Enfermería, en especial, con respecto a la dimensión de la subjetividad en el trabajo nos llevaron a construir un Modelo para los recursos humanos, para la formación de equipos. Utilizamos una metodología cualitativa, con un abordaje constructivista. Para teorizar fue utilizado tres autores de la dinámica grupal. El conjunto de estos estudiosos, del abordaje constructivista y de la dinámica grupal constituyó la matríz teórica del presente estudio. Procurando atender la confiabilidad en la investigación, fue adoptada la triagulación para obtención de los datos, mediante la utilización de tres técnicas: entrevista semiestruturada, observación simple y grupo focal. El análisis de los datos ocurrió durante todo el proceso de colecta y la síntesis, del análises proporcioná los conceptos más sistematizado. Así, los datos depositaron más que el Modelo, apareciendo la Teoría de los Vínculos Profesionales, el cual corresponde a un nueva manera de administrar el trabajo en equipo en la enfermería.
Endereço: Maira Buss Thofehrn

R. Carlos Gomes, 541

96.055-450 - Três Vendas, Pelotas, RS.

E-mail:mairabt@ufpel.tche.br
Artigo original: Pesquisa

Recebido em: 15 de fevereiro de 2006.

Aprovação final: 27 de junho de 2006.

Texto Contexto Enferm, Florianópolis, 2006 Jul-Set; 15(3): 409-17. 


\section{INTRODUZINDO A PROBLEMÁTICA}

A enfermagem, neste estudo, é entendida como uma disciplina profissional, na qual a construção do conhecimento deve ser compreendida a partir da gestão em enfermagem, quanto ao seu processo de trabalho, sob a dimensão da subjetividade. Desta forma, a gestão consiste num conjunto de atitudes do enfermeiro, visando manter a coerência entre o discurso e a ação, junto à equipe de enfermagem e cuja tarefa deste trabalho é o cuidado terapêutico às pessoas em sofrimento físico, psíquico e social que procuram e necessitam de atenção especializada. O cuidado terapêutico consiste na tarefa profissional do processo de trabalho da enfermagem que visa "transformar um estado percebido de desconforto ou dor em um outro estado de mais conforto e menos dor, portanto tem uma perspectiva terapêutica sobre um objeto animado, que tem uma natureza física e social" $1: 39$

Para a compreensão do processo de trabalho na enfermagem sob o prisma da subjetividade é preciso reconhecer as bases filosóficas e tecnológicas do ato de cuidar, pois apresenta-se como um trabalho cooperativo, por ser executado por uma equipe*, na contingência de ser um trabalho de continuidade, de uma equipe para a outra nas vinte quatro horas do dia. Essa compreensão parte, ainda, da necessidade de interligação da dupla condição imposta pelo próprio trabalho, ou seja, de um lado caracteriza-se como um meio de sobrevivência e, de outro, como realização do sujeito, envolvendo as questões subjetivas nas relações interpessoais.

Observa-se, na literatura de enfermagem, uma ênfase significativa ao estudo e prática do trabalho em grupo com clientes, especialmente na área de saúde comunitária. Porém, quanto ao trabalho em equipe na enfermagem existe uma carência de modelos para formação de um grupo de trabalho coeso, com vínculos agregadores que favoreça o desenvolvimento do cuidado terapêutico às pessoas necessitadas. Assim, procuramos, com esse estudo, instigar a enfermagem a transcenderem de uma prática estruturada, para uma prática dinâmica levando em consideração as relações dos sujeitos no tempo, nos espaços indo além das tecnologias disponíveis. A busca pelo encantamento dos profissionais pelo seu trabalho, "vindo da arte de seduzir a si e aos outros". 2:40

Os conteúdos de administração e gestão em enfermagem são entendidos nesse estudo, como instrumentos de trabalho importantes para a realização da tarefa profissional, ou seja, o cuidado terapêutico à clientela atendida, e nos sentimos envolvidas neste processo de amadurecimento profissional, para entender e considerar cada atividade realizada como uma face importante do processo de trabalho do enfermeiro, cada qual com suas características próprias.

Desta forma, cabe ao enfermeiro determinar, juntamente com sua equipe, as ações a serem desenvolvidas pelos seus membros, inclusive as suas próprias atividades. Mesmo não prestando todos os cuidados, este profissional responde legalmente pelos atos da equipe de enfermagem e desta forma necessita estar próximo tanto da equipe quanto do cliente, de modo que é necessário revisar e reconstruir a identidade gerencial do enfermeiro, por meio do envolvimento do profissional, internamente, além da articulação e interação dos diversos atores e segmentos institucionais, para consolidar as relações coletivas de trabalho. ${ }^{3}$ A construção da gestão em enfermagem precisa acompanhar as perspectivas hoje em curso em todo mundo, quanto à modernização administrativa, de modo a incluir humanização nos modelos gerenciais.

A partir dessas constatações, o presente estudo tem como proposta abordar as relações interpessoais, identificando o que chamamos de "vínculos profissionais", revitalizando as questões subjetivas, ou seja, o imaginário, o simbólico, a fantasia, o desejo, as ansiedades, de maneira que se tornou possível a construção, com os profissionais de enfermagem, de um Modelo para o trabalho em equipe que acreditamos possa satisfazer tanto as necessidades das pessoas que procuram os serviços de saúde, como dos trabalhadores, constituindo-se num novo modo de gestão em enfermagem.

Em virtude da complexidade dos conceitos que emergiram dos dados coletados no estudo investigativo, foi imperativo avançar para além do Modelo para o trabalho em equipe na enfermagem e propor a Teoria dos Vínculos Profissionais, ou seja, uma sustentação filosófico-teórica ao Modelo.

Assim, o ponto de partida para o desenvolvimento do presente estudo deu-se pelo entendimento da dimensão da subjetividade do trabalho, a partir dos princípios teóricos da dinâmica de grupo que correspondem ao campo de estudo e pesquisa dos 
fenômenos de funcionamento dos grupos, classificação e maneiras de comportamentos coletivos. ${ }^{3}$

Este novo modo de gestão, ou seja, uma proposta de Teoria dos Vínculos Profissionais que emergiu da construção do Modelo para o trabalho em equipe na enfermagem, é entendido como um instrumento de trabalho, uma ferramenta mediadora ${ }^{\dagger}$, podendo agir na subjetividade no trabalho, favorecendo o alívio subjetivo das dificuldades, do desgaste físico, em suma, do sofrimento presente nas atividades normativas e rotineiras, tornando o ambiente de atuação agradável, com capacidade de produzir alegria, prazer e satisfação, para em última instância, auxiliar no desenvolvimento de um cuidado coletivo que atenda as necessidades das pessoas que procuram os serviços de saúde.

Assim, o objetivo do presente estudo foi construir um Modelo de trabalho em equipe na enfermagem, que favoreça as relações interpessoais, ou seja, os vínculos profissionais, para o alcance de um cuidado terapêutico comprometido com as pessoas que necessitam de atendimento nas instituições de saúde.

A tese ficou assim constituída: "um modelo de trabalho que considere a dinâmica das relações interpessoais na equipe de enfermagem, na perspectiva de uma práxis crítica, reflexiva e participativa, favorece a formação e afirmação de vínculos profissionais, possibilitando a realização do trabalho de enfermagem em consonância com parâmetros de competência ética". $4: 32$

\section{METODOLOGIA}

Com vistas à construção de um Modelo para o trabalho em equipe, propondo assim um novo modo de gestão em enfermagem, fomos buscar subsídios para respaldar a trajetória metodológica da presente investigação na corrente construtivista do pensamento, de forma geral, e no referencial teórico utilizado nesse trabalho, ou seja, a Teoria da Atividade. 5,6

Sendo coerente com a abordagem construtivista, esta pesquisa utiliza-se de abordagem qualitativa, com característica exploratória e descritiva. Apresenta o construtivismo como um método alternativo que prima pela flexibilidade e adaptação, partindo da interação entre o racional e o intuitivo na análise do fenômeno.?

Com vistas a atender à confiabilidade na pes- quisa construtivista, foi adotada a triangulação na obtenção de dados, assim, a coleta de dados ocorreu mediante a utilização de três técnicas, ou seja, entrevista semi-estruturada, observação simples e grupo focal. A triangulação corresponde a métodos diferentes para examinar o mesmo fenômeno sob várias perspectivas e, expandir o entendimento acerca da situação investigada. ${ }^{8}$ Ainda, a pesquisa construtivista tem fases determinadas, as quais apresentamos a seguir.

A primeira fase, de entrevista, inicialmente era um estudo prévio, a qual passou a integrar-se como uma das fases dessa investigação devido a sua importância e abrangência, pois permitiu uma visão mais concreta das relações estabelecidas no trabalho da enfermagem. Os dados da fase de entrevista foram colhidos durante o mês de setembro de 2001, quando foram entrevistadas doze enfermeiras que desenvolvem suas atividades profissionais em três hospitais gerais e em uma escola de enfermagem, numa cidade do interior da região sul do Brasil, sendo três de cada entidade.

A segunda fase, de observação do processo de trabalho em equipe de enfermagem, teve efetivação após o aprofundamento bibliográfico acerca do tema gestão em enfermagem, processo de trabalho e dimensão da subjetividade. Três equipes de enfermagem foram observadas no período de outubro a dezembro de 2002. A observação simples ocorreu durante períodos intermitentes de duas horas, e registros subseqüentes, em diferentes turnos de trabalho, totalizando 35 horas de observação. Por conveniência, foram selecionadas duas instituições hospitalares e um posto de atenção primária da rede básica municipal de saúde. Nos meses de janeiro e fevereiro de 2003, os dados contidos no diário de campo foram apreciados por todos os participantes das equipes observadas e os mesmos foram validados. Os participantes além do codinome de flores foram codificados como (E) para enfermeiros e (EE) para todos os demais membros da equipe de enfermagem.

Para a última fase, de construção do Modelo para o trabalho em equipe na enfermagem, foi utilizada a técnica de grupo focal, entendida como um modo de coletar dados a partir das experiências, discussões, percepções em grupo a partir de um amplo debate. ${ }^{9}$ Os participantes foram selecionados de forma a preencher os critérios para a obtenção do máximo de

\footnotetext{
$\dagger$ ferramenta mediadora éfundamental na relação do ser humano com o mundo e as demais pessoas. Para o desenvolvimento das funções psicológicas superiores, isto é, desenvolvimento intelectual que a pessoa estabelece, com o contexto social no qual está inserido, uma relação indireta, uma relação mediadaporferramentas auxiliares da atividade bumana., ${ }^{5,6}$
}

Texto Contexto Enferm, Florianópolis, 2006 Jul-Set; 15(3): 409-17. 
dados variáveis sobre a realidade estudada. Para alcançar o objetivo da pesquisa foram realizados onze encontros. O grupo contou com a participação efetiva de dez pessoas, assim distribuídos: oito enfermeiros, um auxiliar de enfermagem e um acadêmico de enfermagem, contemplando assim, a recomendação de participantes por grupo focal que devem ser, idealmente, entre seis e quinze pessoas. ${ }^{9,10}$

A fase de construção contou com o desenvolvimento de três etapas: primeira etapa de estudo e construção do Modelo para o trabalho em equipe na enfermagem; segunda etapa: parada reflexiva, para interiorização da temática debatida na primeira etapa; terceira etapa: mediante um encontro para complementação de alguns conceitos do Modelo para o trabalho em equipe na enfermagem e validação do mesmo.

O projeto foi aprovado pelo Comitê de Ética em Pesquisa da Faculdade de Medicina da Universidade Federal de Pelotas, ofício número 060/2002. Os demais aspectos éticos respeitaram a Resolução no 196/ 96 do Ministério da Saúde, que trata da pesquisa envolvendo seres humanos e estiveram presentes desde a seleção dos participantes e durante as três etapas da pesquisa. ${ }^{11}$ Após a assinatura individual do consentimento livre e esclarecido, foi garantido sigilo e anonimato, bem como acesso aos dados e liberdade de desistir do estudo quando o desejassem, os participantes receberam codificação por meio de nome de flores, a seu critério de escolha.

A validação dos dados refere-se ao rigor científico e na pesquisa construtivista, a confiabilidade é responsável pela qualidade do resultado da investigação. ${ }^{9}$ Visando atender essa característica, foi utilizada a triangulação com três técnicas distintas de coleta de dados. Após uma análise mais apurada dos dados colhidos, o Modelo para o trabalho em equipe na enfermagem foi reelaborado e, então, apresentado e discutido em dois encontros, para ser validado.

O primeiro encontro ocorreu no dia vinte de novembro de 2003, quando foi apresentado o Modelo, como pauta única, no Núcleo de Estudos e Pesquisa sobre Trabalho, Saúde e Cidadania da Universidade Federal de Santa Catarina. O segundo momento de validação transcorreu no dia quatro de dezembro de 2003, no qual foram convidados todos os profissionais que participaram das três fases de coleta de dados e, ainda, alguns enfermeiros com experiência junto a atuação em equipes. Após discussão e síntese, os participantes dos dois encontros apontaram algumas sugestões para incrementação do Modelo e, em se- guida, o mesmo foi aprovado por unanimidade.

A análise dos dados foi um processo complexo de organização e interpretação dos dados, que acompanhou todo o processo de investigação. $\mathrm{Na}$ medida em que os dados foram sendo colhidos, a pesquisadora procurou identificar os temas, numa contínua reelaboração dos mesmos, a cada nova interpretação ou complementação. $\mathrm{O}$ modo de fazer do procedimento de análise se estruturou em torno do propósito deste estudo, um Modelo para o trabalho em equipe, enquanto um novo modo de gestão em enfermagem, a partir das relações interpessoais, numa perspectiva dialética e histórica, buscando ir do microespaço à comunidade social, da parte ao todo, para finalizar com uma proposta prática, na formulação de uma metodologia para o desenvolvimento de Vínculos Profissionais.

\section{APRESENTAÇÃO E ANÁLISE DOS DA- DOS}

Com vistas a facilitar a compreensão da apresentação dos dados, foram agrupados os dados da entrevista e da observação e os dados do grupo focal são apresentados separadamente, por terem sido coletados sob uma perspectiva de construção de um Modelo para o trabalho em equipe na enfermagem. Quanto aos dados da entrevista e da observação após análise, os resultados serão apresentados em forma de temas, categorias e conteúdos expressos.

\section{Apresentação de dados originados nas entre- vistas e observações}

Primeiro tema: posição individual e grupal no microespaço de atuação. Este tema diz respeito ao modo como os profissionais se apresentam em relação ao seu trabalho, e como percebem a equipe na qual estão inseridos, apresentamos a seguir as categorias que emergiram.

Quanto ao preparo acadêmico sobre relações grupais, esta categoria representa as percepções relativas ao preparo necessário à execução do trabalho, na formação acadêmica. Na maioria das vezes, a Escola atua mais como um estímulo do que para uma formação acabada e definitiva.

Nivel de graduação éponquíssimo[...] da graduação, talvez o estímulo inicial [...] falta maispassos sistematizados [...](Bromélia).

Preparo no ambiente de trabalho sobre relações grupais, esta categoria representa as percepções 
relativas ao preparo necessário à execução do trabalho por meio do aprimoramento contínuo diante $\mathrm{da}$ necessidade de novas competências ou habilidades. Identificamos a necessidade de um preparo para o trabalho em grupo na enfermagem, pois a maioria dos enfermeiros entrevistados verbalizou que a formação de sua equipe de trabalho ocorreu mediante a atuação na prática profissional, ou seja, pelo método do "erro e acerto".

Segundo tema: movimento das relações grupais. Refere-se à vida em grupo, a qual oportuniza um universo de experiências, para o desenvolvimento e crescimento das pessoas, a partir da descoberta de si mesmo e dos outros, conforme identificado nas categorias que a seguir passamos a apresentar.

$\mathrm{Na}$ categoria introdução ao tema, os enfermeiros relacionam a dinâmica de grupo como um instrumento para promover maior conhecimento entre as pessoas e, conseqüentemente, formação de um grupo. A dinâmica de grupo corresponde ao movimento existente no grupo, superação do individual e construção do coletivo. ${ }^{12}$

\section{[...] atividade que as pessoas vão se mexer, seja o corpo, seja amente(Rosa).}

[...] servepara relaxar, para descontrair, confraternizar[...] (Begônia).

A partir dessas falas percebemos a existência de um conceito predeterminado entre os enfermeiros entrevistados, sobre dinâmica de grupo, e em seu imaginário está consolidada a idéia de dinâmica de grupo enquanto técnicas para condução do grupo.

A categoria processo de integração, corresponde à formação de um processo social que tende a harmonizar e unificar diversas unidades, em alguns casos até unidades antagônicas. Ficando claro através dos conteúdos expressos: autoconhecimento, processo de interação, aceitação do outro, e formas de abordar o grupo. $n a(\operatorname{Ros} a)$.

A pessoa tem que mudar a partir de uma reflexão interdas(Íris).

Diferentespessoastêm diferentesformas deseremaborda-

A categoria cooperação está relacionada ao desenvolvimento da tarefa profissional de forma conjunta, com a utilização das aptidões individuais e singulares para o coletivo de trabalho e os conteúdos expressos são: envolvimento no grupo, amizade, solidariedade e comprometimento com o trabalho.

Lágrima-de-cristo(EE) deformasorridente dirige-se até
Tulipa (EE), para auxiliá-la na realização dos cuidados de bigienee conforto a cliente(Observação).

Quanto à categoria definição de papéis, percebemos a sua importante num grupo, pois determina as ações específicas para cada membro da equipe, sempre em conformidade com a lei do exercício profissional, mas este processo precisa ser algo flexível e determinado por cada grupo, dentro de seu contexto social, a partir de um consenso frente às responsabilidades de cada participante.

A categoria reunião foi percebida por ter uma existência regular e que favorece o desenvolvimento social do grupo, o surgimento da criatividade e de descobertas pessoais e coletivas que devem visar o aprimoramento do comportamento, do rendimento, das relações, assim como, minimizam as dificuldades inerentes à vida cotidiana dos grupos. ${ }^{13}$

Com referência a categoria relações de poder, foi identificada nas entrevistas e nas observações como uma categoria significativa, pois é mediante a forma de condução das relações de poder que se desencadeará a formação e afirmação de vínculos profissionais que levem ao desenvolvimento grupal, a partir da atenção aos seguintes conteúdos: liderança democrática e participativa, comando de subordinados com coerção, em prol de um desenvolvimento coletivo para o reconhecimento profissional.

O terceiro tema refere-se ao processo de comunicação. A comunicação entre as pessoas é complexa e particular, pois corresponde a manifestação do sistema de linguagem e pensamento que é traduzido por signos, ou seja, idéias, sentimentos, desejos, a partir de um contexto sócio-cultural-histórico, determinando uma experiência pessoal e singular. ${ }^{14} \mathrm{Os}$ informantes e as equipes observadas apontaram várias dificuldades na comunicação que categorizamos como ruídos na comunicação, a qual está muito relacionada à insegurança pessoal, medo de se exporem ou de serem mal interpretados, ainda, medo de sofrer com reações negativas e de descrédito.

[...] Essa falta de franqueza, de abertura, as coisas se dãoem bastidores, vão minando relações, daqui apouco vocênão tem mais um grupo (Íris).

Foi identificado e observado que é possível se atenuar esse processo de insegurança, mediante a categoria seguinte, a comunicação positiva, entendida pela ocorrência de um diálogo aberto e igualitário, com uma comunicação autêntica e transparente.

O quarto tema, educação continuada, é apontado como vital para o ser humano, para o aprimora-

Texto Contexto Enferm, Florianópolis, 2006 Jul-Set; 15(3): 409-17. 
mento nas dimensões pessoal e profissional e para acompanhar a atual concepção de mundo do trabalho. ${ }^{15}$

A categoria aprimoramento profissional, faz-se necessária em virtude das profundas modificações que estão ocorrendo nas instituições de saúde, afetando a todo o momento o grupo de trabalhadores, determinando um futuro impreciso, cheio de vicissitudes, mudanças e incertezas, assim o conteúdo expresso refere-se à busca de crescimento como pessoa e como trabalhador.

A educação em serviço é uma categoria entendida como o acompanhamento, por parte do enfermeiro, dos demais participantes da equipe de enfermagem, durante a própria jornada de trabalho, no intuito de desenvolver a competência profissional, pelo aperfeiçoamento técnico-científico do agir na enfermagem.

Cíclame(E) orienta Dama-da-noite(EE) e demonstra atécnica de preparo de material a ser esterilizado, com atenção, presteza erespeito(Observação).
A categoria competência profissional consiste na capacidade ético-legal, aptidão que o profissional da enfermagem tem de apreciar, executar e responder por questões que envolvem o cuidado terapêutico, em conformidade com a Lei do Exercício Profissional e o Código de Ética dos Profissionais da Enfermagem, cujos conteúdos expressos referem-se ao conhecimento da unidade e à supervisão da equipe de enfermagem. ${ }^{16}$

\section{Apresentação dos dados originados do gru-} po focal

Os dados apresentados a seguir correspondem ao resultado do trabalho do grupo focal, no qual tentamos, enquanto pesquisadoras construtivistas, primar pela flexibilidade, adaptação e participante do grupo. Passamos a apresentar a síntese do Modelo para o trabalho em equipe na enfermagem, construído pelo Grupo Vínculo, denominação estabelecida, por consenso, pelos próprios participantes dessa fase da pesquisa.

\section{Processo de trabalho da enfermagem: tarefa profissional, objeto de trab alho}

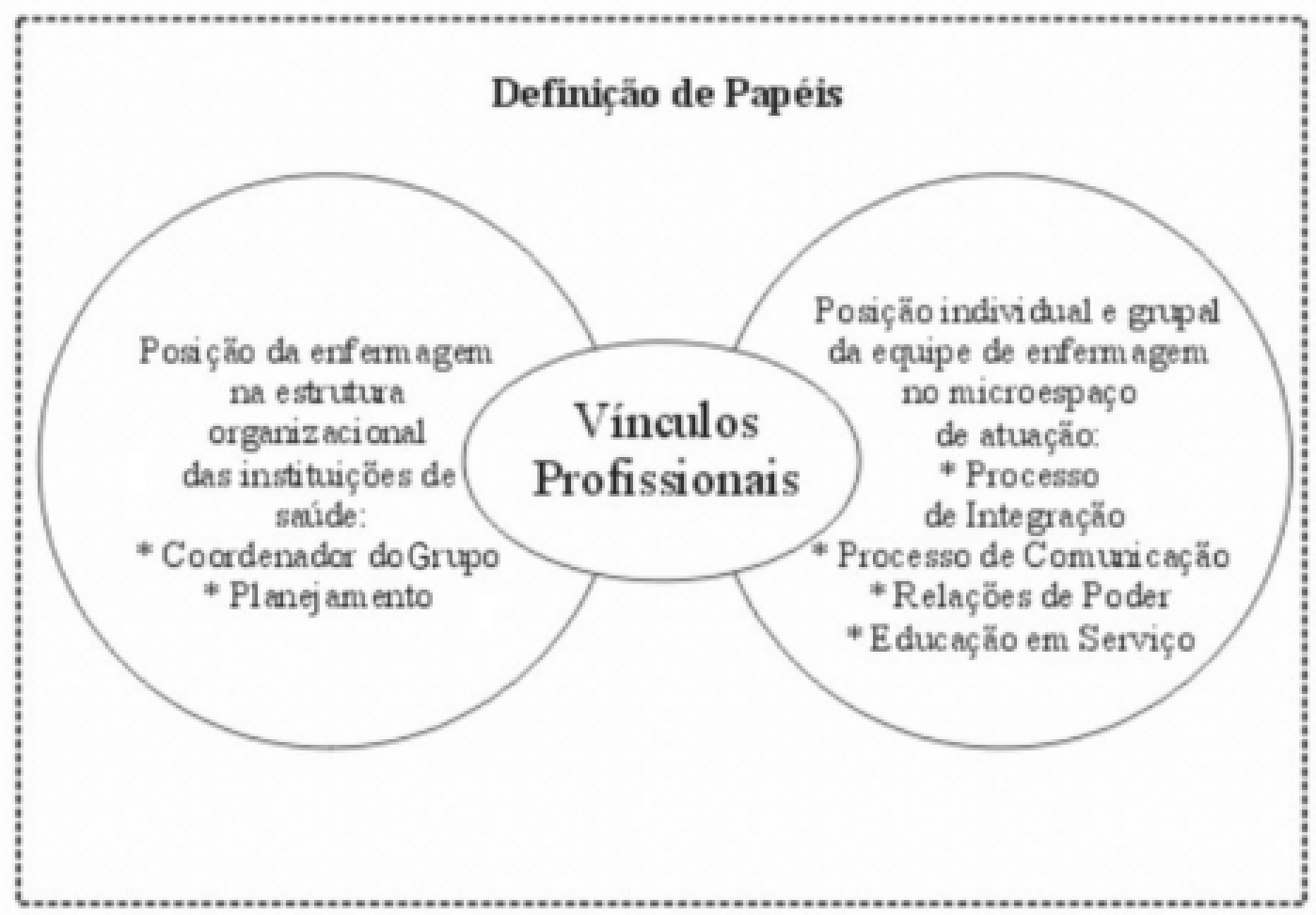

Instrumental, fim/finalidade $e$ força de trabalho

Figura 1 - Modelo para o trabalho em equipe na enfermagem: construção Grupo Vínculo. 
Apresentação do modelo para o trabalho em equipe na enfermagem

Na pesquisa construtivista, a motivação é essencial e a evolução intelectual encontram-se em contínuo amadurecimento. Desta forma motivadas com os resultados obtidos no Grupo Vínculo, retomamos e re- lemos os dados colhidos na fase de entrevista e na fase de observação e pudemos, então, retomar os esquemas existentes naquele momento. Assim, apresentamos de forma esquemática, o novo Modelo, como a primeira síntese da análise dos dados colhidos adicionada às sugestões dos participantes dos encontros de validação do Modelo.

\section{Processo de trabalho da enfermagem: tarefa profissional, objeto de trab alho}

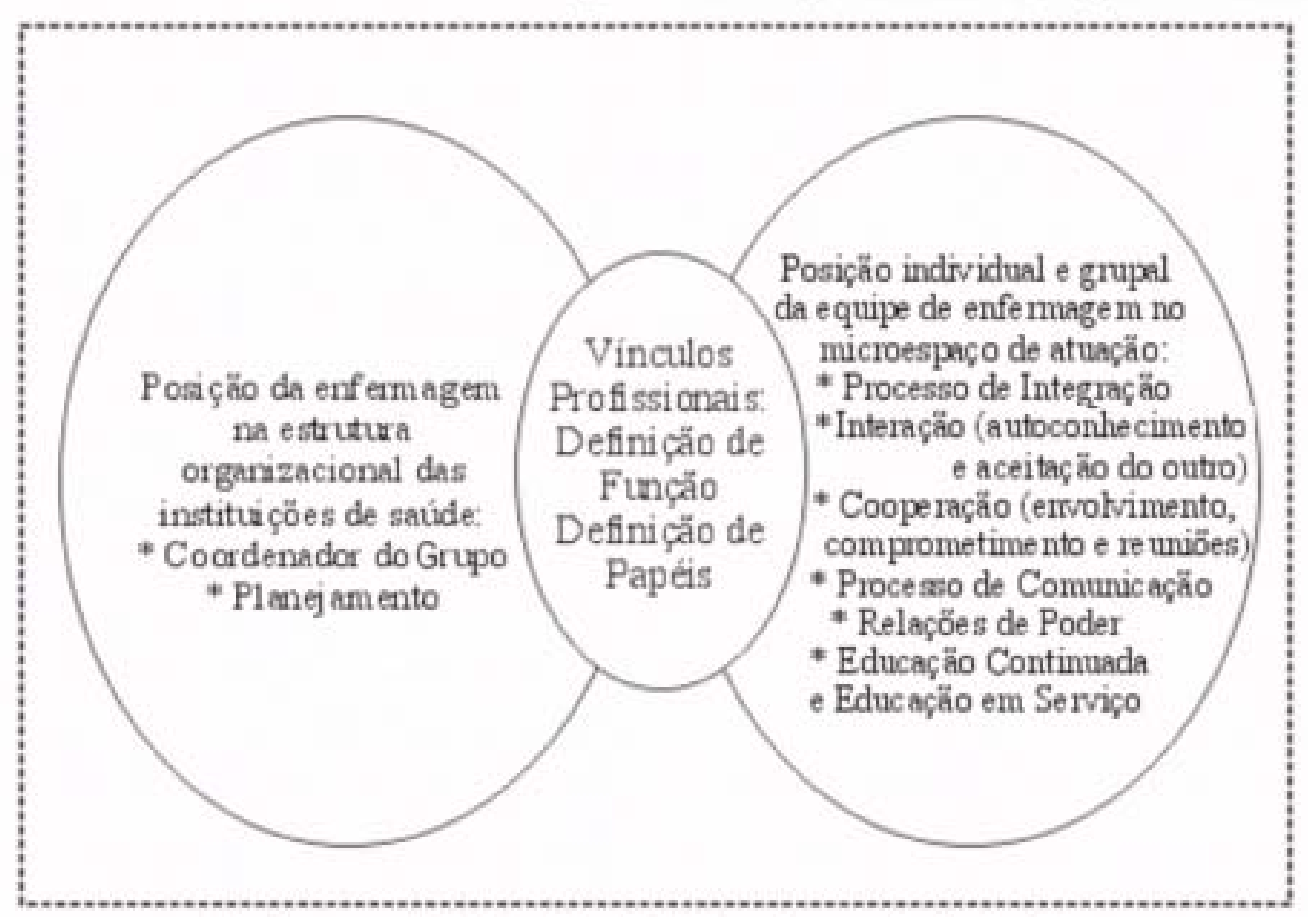

Instrumental, fim/finalidade e força de trabalho

Figura 2 - Modelo para o trabalho em equipe na enfermagem - primeira síntese dos dados.

Como a pesquisa construtivista é relacionista e transformista, possui uma abordagem repleta de possibilidades e aberturas. No caso do presente estudo, a construção do Modelo para o trabalho em equipe em enfermagem nos encaminhou para o aprofundamento da questão em pauta, surgindo assim a Teoria dos Vínculos Profissionais. ${ }^{5}$

\section{NA PERSPECTIVA DE UMA "TEORIA DOS VÍNCULOS PROFISSIONAIS”}

A Teoria dos Vínculos Profissionais consiste num conjunto de conceitos e estratégias gerais, tanto na direção da realização dos trabalhadores da equipe, quanto em relação aos resultados de qualidade pretendidos. É uma concepção relacional na busca do fortalecimento da equipe, visando contribuir para um novo modo de gestão em enfermagem. A nova síntese entre a proposta obtida pela análise dos dados e as idéias preconizadas pelos diferentes autores, tornou possível apresentarmos conceitos explicitados e articulados, formando assim a Teoria dos Vínculos Profissionais, de acordo com o esquema. 


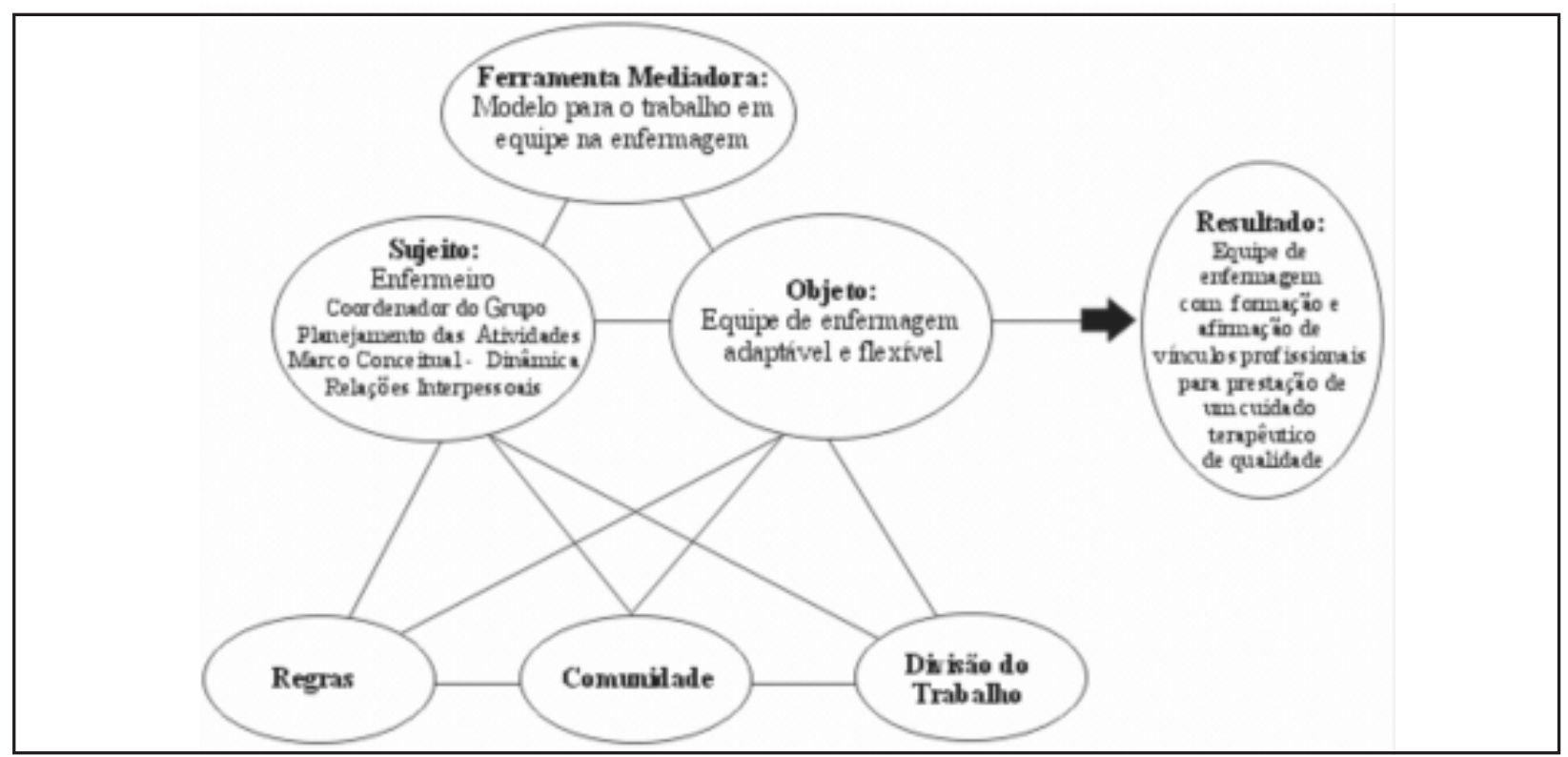

Figura 3 - Teoria dos Vínculos Profissionais.

$\mathrm{Na}$ Teoria dos Vínculos Profissionais, o Modelo para o trabalho em equipe na enfermagem consiste numa ferramenta mediadora para o trabalho estabelecido por meio de conceitos, que serve como referências para as relações interpessoais entre profissionais. Consiste em um conjunto de ações que visam tornar o ambiente de trabalho um local de realizações e, principalmente, de desenvolvimento do indivíduo, enquanto pessoa e profissional, favorecendo a interação no coletivo. ${ }^{6}$

O Modelo para o trabalho em equipe na enfer- magem é uma metodologia que visa subsidiar o sujeito, no caso, o enfermeiro com os conhecimentos teórico-práticos da dimensão da subjetividade no traba1ho. Considerando que o enfermeiro é o coordenador da equipe, esse Modelo também tem o propósito de auxiliá-lo em sua atividade gerencial.

A seguir, apresentamos de forma esquemática, os conceitos que fazem parte de duas vertentes que formam o Modelo para o trabalho em equipe na enfermagem.

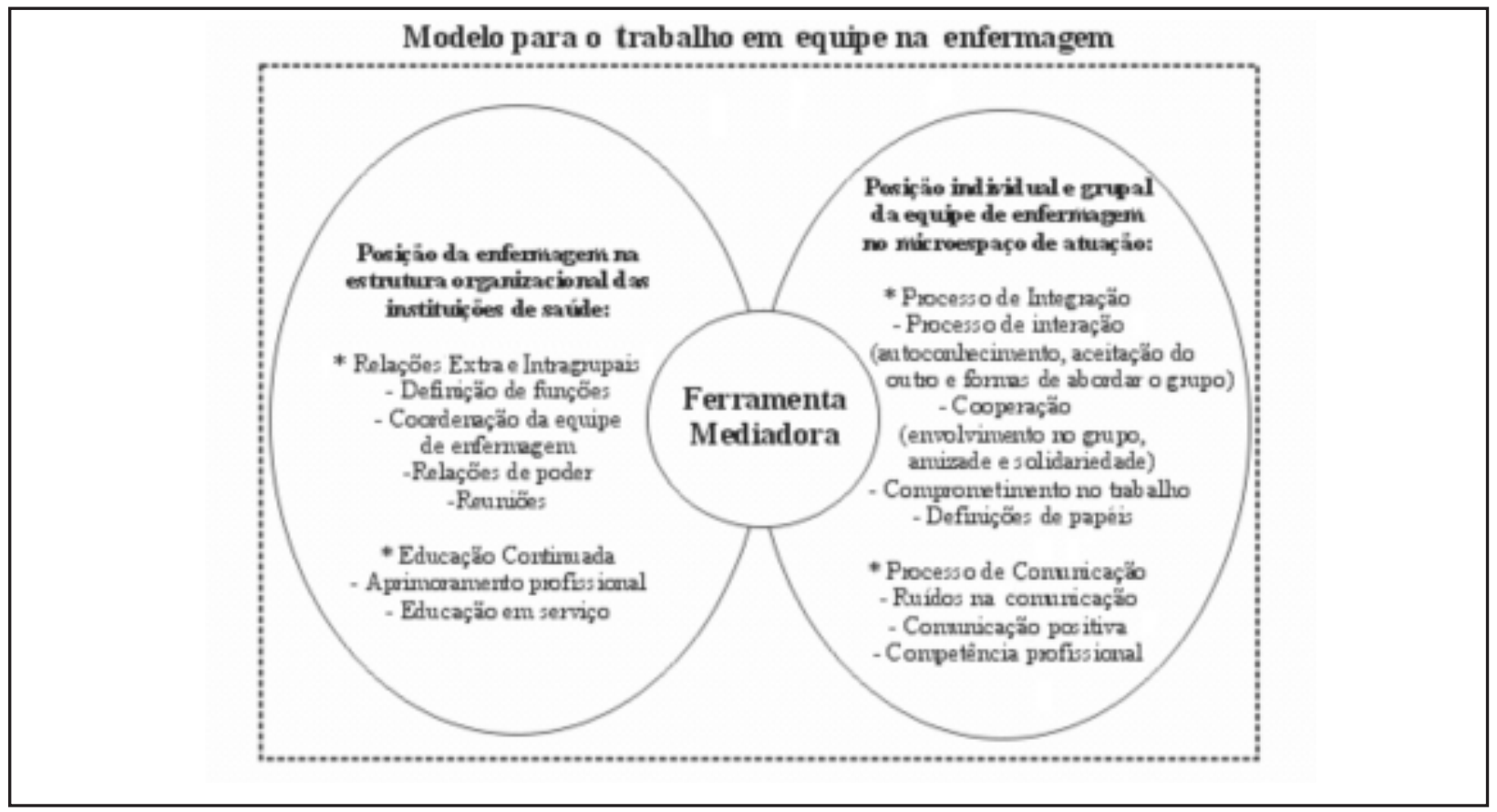

Figura 4 - Modelo para o trabalho em equipe na enfermagem: ferramenta mediadora. 
A Teoria dos Vínculos Profissionais pode tornarse o discurso inovador para um novo modo de gestão em enfermagem, cujo resultado é a prática de ações profissionais éticas no seu sentido mais amplo, favorecendo o bem-estar das pessoas, pela capacidade tecnicamente elevada da equipe de enfermagem, mas também porque esta equipe terá oportunidade de se realizar mais em seu trabalho, uma vez consolidada a gestão participativa dos conflitos e a possibilidade da expressão subjetiva na atuação profissional.

\section{CONSIDERAÇÕES FINAIS}

Cada equipe de enfermagem representa um grupo de trabalho único que não se repete, tendo uma dinâmica de relações que, em geral, se consolida de forma espontânea, carregando, muitas vezes, desarmonia e conflitos por um longo tempo, fazendo com que o trabalho torne-se uma jornada de sofrimento e desprazer.

No novo modo de gestão em enfermagem propõe-se que o enfermeiro tenha como objeto de trabalho a equipe de enfermagem e que este esteja consciente da necessidade de atentar para a divisão do trabalho, condição imposta pela sociedade moderna que fez desencadear o aparecimento das especialidades e com elas a fragmentação da prática, que tem levado ao reducionismo, favorecendo o individualismo e o "ensimesmar-se”.

Para romper este ciclo, há necessidade, apesar de e com a vigência das especializações, de resgatar a pessoa em seu contexto sócio-histórico-cultural, a fim de promover meios de cooperação para o alcance de fins solidários, durante a execução do processo de trabalho em saúde.

Frente à realidade apresentada, ousamos construir uma ferramenta mediadora, um Modelo para o trabalho em equipe na enfermagem, considerando a dimensão da subjetividade no trabalho, pela corrente da dinâmica das relações interpessoais. Para nossa surpresa, além de atingir o objetivo proposto nesta pesquisa, foi possível superá-lo, pois ao nos depararmos com os dados coletados, vimos emergir um conjunto de conceitos que nos levaram a pensar na perspectiva de uma Teoria dos Vínculos Profissionais, servindo como um novo modo de gestão em enfermagem, de forma a assegurar o desenvolvimento de atividades coletivas, nas quais as relações interpessoais possam favorecer uma práxis crítica, reflexiva e participativa.

\section{REFERÊNCIAS}

1 Leopardi MT, Gelbcke FL, Ramos FRS. Cuidado: objeto de trabalho ou objeto epistemológico da Enfermagem? Texto Contexto Enferm. 2001 Jan-Abr; 10 (1): 32-49.

2 Erdmann RH, Erdmann AL. O marketing e a enfermagem: a conquista de uma imagem encantadora do profissionalismo. Texto Contexto Enferm. 1996 Jul-Dez; 5 (2): 3542.

3 Zimerman DE. Fundamentos básicos das grupoterapias. Porto Alegre (RS): Artes Médicas Sul; 1993.

4 Thofehrn MB. Vínculos Profissionais: uma proposta para o trabalho em equipe na enfermagem [tese]. Florianópolis (SC): Programa de Pós-graduação em Enfermagem/UFSC; 2005.

5 Leontiev AN. Actividad, conscienciay personalidad. Buenos Aires (AR): Ediciones Ciencias del Hombre; 1978.

6 Vygotsky LS. Formação social da mente. 6a ed. São Paulo (SP): Martins Fontes; 1998.

7 Rodwell MK. Social work constructivist research. New York/London(USA/FR): Garland Publishing; 1998.

8 Leopardi MT. Critérios de confiabilidade e validez. In: Leopardi ML, Beck CLC, Nietsche EA, Gonzales, RMB. Metodologia da pesquisa na saúde. Santa Maria (RS): Pallotti; 2001. p.251-6.

9 Beck CLC, Gonzales, RMB, Leopardi ML. Técnicas e procedimentos de pesquisa qualitativa. In: Leopardi ML, Beck CLC, Nietsche EA, Gonzales, RMB. Metodologia da pesquisa na saúde. Santa Maria (RS): Pallotti; 2001. p.25781.

10 Dall'agnol CM, Trench MH. Grupos focais como estratégia metodológica em pesquisas na enfermagem. Rev. Gaúcha Enferm. 1999 Jan; 20 (1): 5-25.

11 Ministério da Saúde (BR), Conselho Nacional de Saúde, Comitê de Ética em Pesquisa em Seres Humanos. Resolução No 196 de 10 de outubro de 1996: diretrizes e normas regulamentadoras de pesquisas envolvendo seres humanos. Brasília (DF): O Conselho; 1996.

12 Zimerman DE. Fundamentos teóricos. In: Zimerman DE, Osório LC, organizadores. Como trabalhamos com grupos. Porto Alegre (RS): Artes Médicas; 1997. p.23-31.

13 Contreras JM. Como trabalhar em grupo. São Paulo (SP): Paulus; 1999.

14 Vygotsky LS. A construção do pensamento e da linguagem. São Paulo (SP): Martins Fontes; 2000.

15 Backes VMS, Schmidt SMS, Nietsche EB, Saurin MHG, Ferraz F. Educação continuada: algumas considerações na história da educação e os reflexos na enfermagem. Texto Contexto Enferm. 2003 Jan-Mar; 12 (1): 80-8.

16 Conselho Regional de Enfermagem, Seção RS. Legislação. Porto Alegre (SP): O Conselho; 1999. 